\title{
E. P. Thompson entre fragmentos, embates e tensões: reflexões teórico- metodológicas do seu posicionamento frente aos escritos de Anderson, Nairn e Kolakowski
}

E. P. Thompson between fragments, embates and tensions: theoretical-methodological reflections of its positioning in front of Anderson's, Nairn and Kolalowski's writings

Lucas Pereira de Oliveira*

\section{Resumo}

Este artigo tem por objetivo problematizar o posicionamento do historiador inglês E. P. Thompson frente às discussões tratas por teóricos como P. Anderson, Nairn e Kolakowski. As principais questões discutidas neste ensaio se darão a partir da reflexão que Thompson trouxe, ao refutar e problematizar as compreensões teóricas relativas à leitura do marxismo (e suas nuances) e ao lugar do historiador no processo da escrita. Metodologicamente, utilizamos como fonte de análise, as seguintes obras de Thompson: A miséria da teoria ou um planetário de erros (1981); A peculiaridade dos Ingleses e outros artigos (2001) e a Carta Aberta a Leszek Kolakowski (1973).

Palavras-chaves: Marxismo; Teoria; Experiência; História.

\begin{abstract}
This article aims to problematize the position of the English historian E. P. Thompson in front of the discussions treated by theorists like P. Anderson, Nairn and Kolakowski. The main issues discussed in this essay will be found in Thompson's reflection on refuting and problematizing theoretical understandings concerning the understanding of Marxism (and its nuances) and of the historian's place in the writing process. Methodologically, we use Thompson's works as the source of analysis, namely: The misery of theory or a planetary of errors (1981); The peculiarity of the British and other articles (2001) and the open letter to Leszek Kolakowski (1973).
\end{abstract}

Keywords: Marxism; Theory; Experience; History.

\section{Introdução}

A realidade tem múltiplos sentidos e cada sentido tem, em si, sua pertinência.

(BOURDIEU, 1992, p. 44).

"A História é filha de seu tempo", afirmava Lucien Febvre, nos levando a refletir como os historiadores sempre estarão determinados a questionar seus ofícios dentro das exigências do tempo e lugar em que vivemos. De fato, a dinâmica histórica é mesmo

\footnotetext{
* Doutorando em História pela Universidade Estadual Oeste do Paraná (UNIOESTE).
}

Recebido em setembro de 2017 | Aprovado em abril de 2018. 
essa, é o que cada tempo e espaço exigem dela. Não há dúvidas que cada teoria e concepções conceituais têm sua significação em seus determinados contextos, assim como influenciam para o entendimento da História hoje. Tomamos como centro do nosso debate, uma História que não mais se compromete com a verdade pronta e absoluta, mas exatamente com as várias interpretações de mundo por meio das experiências, embates teóricos, imaginários, sensibilidades, entre outros.

Nesse sentido, nosso objetivo no presente ensaio é problematizar as questões levantadas pelo historiador E. P. Thompson em seus textos: A miséria da teoria ou um planetário de erros (1981); A peculiaridade dos Ingleses e outros artigos (2001) e a Carta Aberta a Leszek Kolakowski (1973). A escolha do detalhamento dessas obras se dá pela crítica contundente do autor a P. Anderson, Nairn, Kolakowski e Althursser, autores que refletem as concepções do marxismo e da ciência histórica em seus meandros teóricos e metodológicos.

Para isso, a formatação teórica desse artigo traz, inicialmente, a trajetória de E. P. Thompson, refletindo suas experiências, haja vista serem elas importantíssimas para a construção de suas bases teóricas, práticas de ação e entendimento do mundo a sua volta. No segundo momento de nossa reflexão, vamos problematizar as principais discussões dos autores mencionados acima e a crítica de Thompson a eles.

\section{Thompson: trajetória e vivências}

Nascido em 1924, em Oxford, na Inglaterra, Edward Palmer Thompson estudou História na Universidade de Cambridge. Entretanto, teve que interromper o curso para servir ao exército contra o nazifascismo durante a $2^{\text {a }}$ Guerra Mundial. É importante ressaltar que Thompson, ainda quando era estudante de História, aderiu ao Partido Comunista da Grã-Bretanha (PCGB).

Com o fim da guerra, voltou à universidade e se formou em 1946 e, aos 24 anos, foi contratado pela Universidade de Leeds para ser professor. Durante esse período, participou ativamente no partido, chegando a formar um grupo com vários historiadores, como Eric Hobsbawm e Christhopher Hill, em que discutiam o marxismo na Inglaterra entre os anos de 1946 e 1956. Uma importante contribuição desse grupo de intelectuais foi a "necessidade de uma compreensão histórica do desenvolvimento do capitalismo inglês numa perspectiva marxista” (FORTES; NEGRO, 2012, p. 31). 
Em decorrência do descobrimento dos crimes de Stalin e da invasão da Hungria pela URSS, vários membros saíram do Partido Comunista, dentre eles Thompson, Raymond Willians e Joah Saville. Eles viriam a constituir-se, em 1956, em um núcleo de movimento político reconhecido como Nova Esquerda e fundaram, na época, uma revista a fim de refletir seus anseios, representando um dos principais periódicos de inspiração marxista no mundo.

Thompson vai desenvolver diversas obras sempre com um viés político muito claro. Ele pública, por exemplo, a biografia de Willian Morris (1955), A formação da classe operária inglesa (1963), As peculiaridades dos ingleses (1965), Senhores e Caçadores (1975), A miséria da teoria ou um planetário de erros (1981) e Costumes em comum (1991). Nesse sentido, seus escritos não podem ser distanciados do seu engajamento político.

\footnotetext{
Segundo o historiador inglês, Christopher Hill, "o marxismo de Thompson era inteiramente alheio a dogmas preconcebidos [...] A tradição marxista abraçada pelo historiador inglês considerava o materialismo histórico como simples e indispensável orientação teórica à pesquisa dos processos históricos. Desde essa perspectiva, Thompson faz a opção por uma História vista a partir de baixo, ao mesmo tempo em que considera a classe e a consciência de classe como conceitos históricos" (FORTES, NEGRO, FONTES, 2012, p. 31).
}

Nesse sentido, a tradição marxista pensada por Thompson propõe uma interpretação aberta e dialética de Marx, contraria à ideia do marxismo como uma doutrina com suas respostas prontas e acabadas, embora tenha sido acusado inúmeras vezes, erroneamente, de ser um historiador apenas culturalista, que não reconhecia o papel das estruturas e das relações de produção como condicionantes da ação humana. Em nossa visão, Thompson representa não só o resgate do "marxismo", mas a figura de um importante teórico para a compreensão de uma História permeada de conflitos, resistência e dominações.

Uma tradição que não pode viver só de Marx, que precisa escarafunchar eternamente a história real, os modos de dominação e as formas de resistência; não apenas a resistência presente no cenário político oficial, mas também aquela diária, incansável [...] (SILVA, 2012, p. 69).

Marc Bloch refletiu em, Apologia da História (2001), que nos paremos mais com nosso tempo do que com nossos pais. Nesse sentido, a intenção de recompor essa trajetória de Thompson é mostrar, já que somos produtos do nosso tempo, que nossa experiência diz muito do que fomos, do que somos e do que projetamos. 


\section{A crítica contundente}

\section{Thompson para Kolakowski}

Neste momento do ensaio, é necessário recompor, por um instante, a trajetória de Kolakowski para entender o posicionamento de E. P. Thompson sobre os escritos desse autor. Dessa maneira, traremos para a discussão um pouco da vida do filósofo, suas abordagens e a crítica de Thompson a ele.

O nascimento de Leszek Kolakowski se deu em 1927, momento em que a Polônia estava tentando se reconstruir politicamente, haja vista a sua divisão desde a queda do rei em 1795. Em Radom, sua cidade natal, Kolalowski teve que interromper seus estudos em virtude da invasão das tropas nazistas em 1939. Assim, refugiou-se com sua família no interior do país, saindo apenas em 1945, quando a $2^{\text {a }}$ Guerra Mundial havia terminado. Depois disso, entra na universidade de Filosofia e filia-se ao Partido Comunista, embevecido de pensamento marxista em virtude da notoriedade que os soviéticos conquistaram com a aniquilação dos nazistas na Polônia.

Kolakowski ganhou reputação de marxista irônico, destoando da imagem severa e sóbria de que gozavam os marxistas do leste europeu. Criticava abertamente os aspectos autoritários da ideologia socialista stalinista, defendendo a criação de um novo modelo de socialismo, que viria chamar de "humanismo marxista", defendendo os ideais de justiça social tradicionais do marxismo, associados a valores como liberdade pessoal e espiritualidade, que estariam excluídos da maioria das correntes marxistas até então (CASSOLI, 2010, p. 6).

É assim que Thompson inicia a sua crítica na Carta Aberta a Leszek Kolakowski. É a partir dessa trajetória que reflete, com pesar, que, embora tenha dito experiências comuns, ele e Kolakowski tiveram vivências de modos distintos, dentro daquilo que se discutia do comunismo como comprometimento político e intelectual com a vertente marxista.

Contudo, depois dessa experiência, ambos tomaram rumos distintos em suas análises, concepções acerca do marxismo e visões de mundo. Thompson relata que "o mundo mudou muito em quinze anos, e nenhum de nós deve ser acusado de inconsistência por mudarmos com ele" (p. 6). Entretanto, ambos deviam lealdade não à instituição do partido comunista, mas ao movimento humanista do mesmo. Seus campos de investigação, nesse sentido, afastam-se dos problemas críticos do Estado e do sistema socialista. 
É diante disso que Thompson escreve uma carta a Kolakowski, no qual reflete pontos que são caros e importantes de serem refletidos e contestados. Podemos destacar, por exemplo, a mudança na tradição da New Left Review ${ }^{l}$ e sua prioridade à análise heurística e estrutural de conceitos e a pouca atenção dada ao empirismo, algo que retomará a discussão em A peculiaridade dos Ingleses e outros artigos, por exemplo.

Podemos identificar também a vivência de diversos tipos de marxismo, o que tem gerado muitos conflitos e desconfortos e ainda a validade do conhecimento histórico.

De acordo com Ramos (2015), refletindo Thompson, os modos de entendimento do marxismo são:

[...] a primeira, como 'doutrina', que busca definir a forma de pensar e agir genuína, por meio de uma seleção de textos e sua justa interpretação, como no stalinismo; segunda, como 'método', com a intenção de estabelecer o método adequado e cientifico de análise derivado dos fundadores, como procuraram fazer, por exemplo, os althusserianos; terceira, como 'herança' tal como pensa Kolakowski, isto é, o pensamento de Marx é apenas mais um que pode/deve compor as ciências humanas e sociais [...] a quarta como tradição (RAMOS, 2015, p. 81).

A partir disso, qual a concepção marxista Kolakowski passou a adotar em seus estudos? Com base na análise de suas obras e seguindo a reflexão de Thompson, o filósofo/historiador segue apenas uma tendência do marxismo como doutrina, ou seja, algo autossuficiente, com respostas dadas a priori. Isso nos parece algo perigoso, pois tratar uma dada realidade com questões já prontas/acabadas e não com base nas evidências empíricas gera uma série de deficiências nas análises.

Para Thompson, o marxismo deve ser abordado como tradição, pois este considera que existem premissas já presentes nos escritos de Karl Marx, porém essas podem ser problematizadas e refletidas por meio do diálogo com teorias e com as evidências empíricas. Isso, ao nosso ver, evitaria uma espécie de cristalização ocorrida nas outras tipologias e aproximar-se-ia da questão do método dialético de análise, proposto por Marx.

Ainda em sua carta aberta, Thompson vai reafirmando sua lealdade e reflete os motivos de se manter fiel à tradição marxista. De acordo com Duayer,

\footnotetext{
${ }^{1}$ A New Left Review (NLR), fundada em 1960, teve, entre seus editores, nomes como Edward Thompson, Perry Anderson e Robin Blackburn. A revista, inicialmente, contemplava as discussões da esquerda e do marxismo. Entretanto, sofreu mudanças na sua estrutura e conteúdo, principalmente, teóricas e políticas.
} 
os marxismos 1 e 2, a despeito das críticas feitas, têm importantes compromissos políticos. Além disso, há também a necessidade de companheirismo, de compromissos, mesmo que acompanhados de críticas e qualificações. Por último, pela própria necessidade teórica de trabalhar no interior de uma tradição e não cair no ecletismo subentendido no marxismo 3 (DUAYER, 2014, p. 9).

Sobre isso, é exatamente aqui que se tem a diferença teórico-metodológica bem evidente entre Thompson e Kolakowski. O primeiro vê que é possível continuar pretendendo ser marxista, já o segundo nega qualquer tradição marxista, chegando por vezes, a colocar em xeque o seu entendimento. Nesse sentido, os dois caminham em direções opostas sobre a compreensão do marxismo e ainda acerca de as dimensões teórica-metodológicas de seus escritos e análises.

Com uma narrativa bastante pessoal e, por vezes, fazendo perguntas contundentes, Thompson diz que "um filósofo pode imaginar uma história livre de valores, mas ele está enganado, e nenhum historiador pode produzi-la" (THOMPSON, 1973, p. 58). Aqui, ele escreve, principalmente, depois de Kolakowski refletir que a História tem, em si mesma, uma inteligibilidade imanente.

Assim, percebemos um campo de disputa entre Thompson e Kolakowski, História e Filosofia. O segundo campo disciplinar parte de uma teorização para explicar a realidade de uma sociedade, já o primeiro saber é mais completo e, conforme Thompson, "a disciplina histórica não é um campo onde diferentes interpretes montam seus estantes e solicitam a preferência dos clientes" (THOMPSON, 1973, p. 63). A História é feita de processo e de evidências. Ela é uma constante construção, pois nada acontece por acaso, visto que tudo é consequência de alguma conjuntura. Os fatos se entrelaçam, sofrem avanços e/ou sinais de recuos, são lembrados ou esquecidos de acordo com as "mãos” dos historiadores. É assim que a História é pensada, produzida e contada.

Por fim, em suas linhas derradeiras, Thompson faz um final ainda mais provocador, "não lhe dei razão para refutar o desespero. Ofereci apenas uma refutação das suas razões particulares para desespero" (THOMPSON, 1973, p. 100). 


\section{Thompson para P. Anderson e T. Nairn}

Aconteceu de um jeito na França e de outro na Inglaterra (THOMPSON, 2001, p. 100)

A peculiaridade dos Ingleses e outros artigos representou para a historiografia um avanço na discussão sobre a tradição marxista e as relações entre teoria e história. Escrita por Thompson, em 1963, e endereçada à crítica dos pensamentos de Perry Anderson e Tom Nairn, essa obra descortina alguns pontos do pensamento desses dois autores, principalmente, quando eles comparam a Revolução Francesa e a Revolução Inglesa, o que vai ser totalmente desconstruída por Thompson.

A nova revista New Left Review ${ }^{2}$, dirigida por P. Anderson, ainda serve de ponto de partida para Thompson iniciar suas críticas, a começar pela falha da experiência histórica $^{3}$ e a relevância do modelo contra o qual está sendo julgada em pelo menos três aspectos:

1) No caráter prematuro e incompleto da revolução do séc. XVII [...]. 2) Porque a revolução do séc. XVII foi "impura" e a luta conduzida em termos religiosos, [...] além de nunca ter desenvolvido uma visão de mundo ou autoconhecimento coerentes, satisfez-se como uma "ideologia" do "empirismo" [...]. 3) Uma revolução burguesa prematura deu origem a um movimento prematuro da classe trabalhadora $[\ldots]^{4}$ (THOMPSON, 2001, p. $80)$.

Perry Anderson e Nairn, na reflexão de Thompson, são apontados como intelectuais ausentes de uma perspectiva mais global da sociedade britânica, ao caírem no equívoco de utilizar "modelos" que não condizem com as peculiaridades inglesas, principalmente, por não enxergarem a noção de uma classe agrária como uma verdadeira burguesia, falta de uma análise mais apurada do proletariado inglês, e por dizerem que a Revolução transformou a estrutura, mas não a supraestrutura inglesa.

\footnotetext{
2 Passados três anos desde a posse da nova direção, parece possível examinar a tendência geral da "novo" New Left Review. Para simplificar, pode-se localizá-la em três áreas principais: análise do "Terceiro Mundo", definições (geralmente evasivas da teoria marxista e o ambicioso trabalho de análise da História e estrutura social britânica, iniciado por meio de uma série de artigos de Anderson e Tom Nairn (THOMPSON, 2001, p. 76).

${ }^{3}$ Toda experiência história é, obviamente, em certo sentido, única. Muito protesto contra isso coloca em questão não a experiência, mas a relevância do modelo contra o qual ela está sendo julgada (THOMPSON, 2001).

${ }^{4}$ Anderson e Nairn preferiam que a Revolução tivesse ocorrida não em torno da religião, mas contra qualquer religião. Acontece que, para Thompson, se a Revolução Inglesa foi disputada em termos religiosos, é porque a religião era importante naquela dada realidade. Não dá para dissociar o contexto vivenciado.
} 


\begin{abstract}
A análise de Anderson traça uma linha depois da revolução inglesa do século XVII, através da qual haveriam sido transformadas as estruturas, mas não as superestruturas da sociedade, uma aristocracia agrária, sustentada por um grupo mercantilista, tornou-se a classe dominante na Grã-Bretanha. O desenvolvimento do capitalismo agrário destruiu o campesinato e a burguesia industrial (que não teria assumido parte de sua tarefa histórica) formaria um bloco com a aristocracia agrária. Neste processo, a classe operária, em formação, foi derrotada e se desenvolveria de forma subalterna, mostrando-se incapaz de transformar a sociedade e tendendo ao corporativismo (MUNHOZ, 1994, p. 160).
\end{abstract}

Diante disso, qual modelo foi adotado por esses autores? O modelo adotado por Anderson e Nairn concentrou, no episódio da Revolução, um ideal, no qual tudo que veio antes ou depois estava relacionado a ela. Mais do que questionar a validade desses modelos, é preciso refletir a sua funcionalidade. Dentre tantas coisas que separam Thompson de Anderson, a definição do campo de análise historiográfica é a mais visível. O segundo é ancorado em uma análise estrutural, já o primeiro trabalha a possibilidade das ações humanas como transformadora da sociedade.

Em A peculiaridade dos ingleses e outros artigos, Thompson fez uma crítica ao modelo estrutural-funcionalista adotado pelos autores, dizendo, por exemplo, que a aristocracia agrária, desde o seu início, foi um componente fundamental para o capitalismo inglês e ainda refletindo que a experiência dessa classe não deve ser descrita como "fragmentada" ou "incompleta", como asseveraram P. Anderson e T. Nairn (THOMPSON, 2001). Pensando nisso, quais modelos são utilizados para reconstruir uma dada realidade? São eles primordiais para compreender uma sociedade?

Em termos teóricos, a abstração de teorias conceituais é importante para pensarmos nossos objetos de pesquisa. Porém, sem uma análise relacional (dialética) da mesma com as evidências (dados empíricos), sendo que estas não conseguem compreender a realidade concreta das ações dos homens e mulheres no tempo. É preciso manter-se aberto à gama de evidências para as quais não tem categorias. Auxiliadas por uma teoria, um modelo, um conceito é que as nossas questões poderão ser respondidas nas fontes.

Como nos lembra Koselleck, uma fonte não pode nos dizer nada daquilo que cabe a nós dizermos. No entanto, "ela nos impede de fazer afirmações que não poderíamos fazer" (KOSELLECK, 2006, p. 188). E é nisso que Anderson e Nairn fraquejam. Transpor realidades apenas no campo dos modelos, sem ter bases empíricas, talvez seja um dos seus maiores pecados. 
Por fim, Thompson ainda faz uma reflexão bastante contundente acerca da crítica à história dos trabalhadores feitas por Anderson e Nairn. Quatro pontos podem ser observados quanto à fraqueza a respeito da análise dos autores. São eles:

1- Inabilidade em compreender o contexto político das ideias e escolhas

2- Ausência da dimensão sociológica em suas análises

3- Vulgarização da noção de hegemonia

4- Falta de discernimento quanto ao impacto do comunismo sobre o movimento britânico (THOMPSON, 2001).

$\mathrm{O}$ que esses pontos representam para a construção de uma realidade sobre a Revolução Inglesa? O primeiro ponto, Thompson diz que Anderson não compreendeu o curso da mudança que estava no centro da classe trabalhadora, pois ele apenas relatou que a tragédia da História foi o fato do marxismo ter passado despercebido pela classe trabalhadora. Em nenhum momento Anderson viu, por exemplo, as associações à esquerda organizadas, influenciando sindicatos e experiências como SDF, Partido Comunista, entre outros. Seu segundo equívoco diz respeito à não compreensão das alianças feitas momentaneamente, o que levaram ao cartismo, por exemplo. Equívoco também no terceiro ponto quando ele emprega termos sem um novo instrumento de análise, mas uma "sofisticação do velho" (THOMPSON, 2001, p. 147). E por fim, temos a carência de compreensão do impacto que o movimento comunista teve sobre a classe e a cultura britânica.

Em seus derradeiros apontamentos, ele convida a reflexão do modo correto do emprego de qualquer modelo, da metáfora da estrutura e supraestrutura, da dificuldade de representação do processo econômico e do conceito de classe. Entendendo classe como uma formação social e cultural dentro de diversas ações e reações, mudanças e conflitos, reduzi-la a "uma identidade é esquecer exatamente onde repousa a 'agência', não na classe, mas nos homens" (THOMPSON, 2001, p. 171).

A epígrafe, "Aconteceu de um jeito na França e de outro na Inglaterra", desse momento do ensaio foi retirada de Thompson e reflete, perfeitamente, a essência da defesa do historiador à obra que critica as reflexões de Anderson e Nairn. O próprio título reflete isso: "peculiaridades", qualidade ou condição do que é peculiar, algo que se distingue dos demais, originalidade, singularidade, ou seja, características inglesas que são próprias de um lugar, por exemplo.

"Os homens nunca fizeram a sua própria história", afirmou Althusser em seus escritos, indagando que a História e o trabalho do historiador não possuem um 
conhecimento verdadeiro, sistematizado e científico. Indagando também que o conhecimento histórico está condenado pela natureza de seu objeto ao empirismo.

Diante disso, ousamos nos questionar? Existe a História um papel científico? Qual a validade de seus estudos? A partir de afirmações e interrogações como estas, E. P. Thompson vai escrever, em 1978, a obra, Miséria da teoria ou um planetário de erros, no qual lança uma importante reflexão sobre a crítica de Althusser. Ele redesenha, desde a prática do materialismo histórico, as bases epistemológicas, a relação entre História e Filosofia até a teoria histórica.

O diálogo travado pelos pensadores P. Anderson, Nairn e Kolakowski no seio do marxismo compreendem pensamentos divergentes. Estudos apontam que:

\begin{abstract}
Uma das objeções cruciais diz respeito à visão thompsoniana do papel do agente humano na história, tema chave de toda a obra do historiador inglês e que se relacionaria com seus caros conceitos de agencia e experiência. Segundo Anderson, se concebemos ação como uma atividade consciente dirigida a objetivos, todos os sujeitos históricos estão envolvidos constantemente em ações das quais são agentes. Entretanto, nem todas as ações tem os mesmos objetivos (MACEDO, 2017, p. 123).
\end{abstract}

Desse modo, é importante compreender que os pensadores P. Anderson, Nairn e Kolakowski possuem concepções marxistas distintas às de Thompson no que tange aos aspectos conceituais e conjunturais. Ambos se aproximam muito das concepções althusserianas e seu enfrentamento no campo essencialmente historiográfico. Thompson, também atento a isso, lança uma importante reflexão à crítica, de forma contundente e perspicaz.

Como uma forma de deslocar as concepções desses teóricos para fora do marxismo, Thompson indaga:

Para mim hoje está claro, a partir do meu exame [...], que já não podemos seguir atribuindo nenhum significado teórico à ideia de uma tradição comum. Pois o abismo que se abriu separa [...] modos de pensamento idealista e materialista, um marxismo como clausura e como uma tradição, derivada de Marx, de investigação e críticas abertas (THOMPSON, 1981, p. 289).

Nessa perspectiva, a crítica endereçada a Kolakowski e especialmente a P. Anderson e Nair vai no sentido de que suas definições e reflexões estruturalistas prejudicam o entendimento do fenômeno da classe (algo tão importante e caro às concepções do próprio Marx), visto que, ao entendê-la deslocada dos processos históricos reais e reduzida apenas a determinações econômicas, apagam por completo o 
dinamismo das relações entre os sujeitos e as experiências (vividas e percebidas) que o constituem enquanto classe.

Desta feita, "a classe não surgiu tal como o sol numa hora determinada. Ela estava presente ao seu próprio fazer-se" (THOMPSON, 1987, p. 9). Partindo desse pressuposto, a classe precisa ser compreendida como fenômeno histórico, assim como a consciência de classe que deve ser processada pelas experiências tratadas também no âmbito cultural, em suas tradições, nuances de valores, ideias e configurações institucionais.

\section{Considerações finais}

Acreditamos que as reflexões trazidas nesse ensaio não esgotam as possibilidades de reflexão sobre tais obras, mas podem funcionar como ponto de partida para outras inquietações.

Podemos identificar que $A$ miséria da teoria representou a crítica a Louis Althusser em, pelo menos, duas vertentes principais. A primeira foi à teórica, que gira em torno da divergência estabelecida entre uma espécie de idealismo e o materialismo histórico, onde o teoricismo oposiciona-se ao empirismo e à lógica histórica. $\mathrm{O}$ outro ponto de divergência principal se dá no campo da política, em que envolve a tutela de uma moralidade comunista e a crítica ao estalinismo. Thompson segue dizendo:

(1) antes que qualquer outra interrogação possa ter início, suas credenciais como fatos históricos devem ser examinadas: como foram registrados? Com que finalidade? Podem ser confirmados por evidências adjacentes? Assim por diante. Este é um aspecto básico do ofício; (2) ao nível de sua própria aparência [se forem] fenômenos culturais ou sociais [apresentam-se] evidências portadoras de valor [...] (3) como evidências isentas de valor [...] (4) como elos numa série linear de ocorrências [visto que] na construção de uma exposição narrativa [...] (5) como elos numa série lateral de relações sociais/ideológicas/econômicas/políticas [...] (6) [...] mesmo fatos isolados podem ser interrogados em busca de evidências que sustentam a estrutura. (THOMPSON, 1981, p. 38-39).

A Carta Aberta a Leszek Kolakowski, com sua narrativa provocadora e reflexiva, nos leva a pensar acerca de o perigo das análises estruturalistas que, constituem um risco a teoria histórica e ao marxismo. E mesmo o método de investigação de Leszek Kolakowski apresenta problemas, pois pensar a investigação dos homens e mulheres de uma dada temporalidade separada de sua cultura é propor uma abstração irreal. O uso de estruturas, superestruturas e conceitos como arquétipos a ser compactados para o real é 
irracional e pouco improvável de ser eficaz e eficiente, haja vista ele não dar conta das dimensões peculiares da sociedade.

Nesse sentido, Thompson avança na discussão de $A$ peculiaridade dos Ingleses $e$ outros artigos, quando ele problematiza os modelos no qual se utilizamos, apontando que, de certa maneira, os mesmos apagam a realidade única daqueles espaços. Não dá para utilizar-se de modelos de um lugar e encaixar em outras realidades, como foi feito por Perry Anderson, cujo modelo de Revolução Francesa foi levado à Revolução Inglesa. Esse erro apontado por E. P. Thompson ocasiona na construção de uma realidade não real e desconsidera, por completo, as evidências de cada período e espaço de uma dada sociedade.

Por fim, a retomada da crítica thompsoniana a P. Anderson, Nairn, Kolakowski e Althursser representa para nós, historiadores, um norte e vários pontos de reflexão que não se esgotarão em nosso metiê: que tipo de conhecimento o historiador produz? Qual a sua validade? Que dimensão política somos levados em nossos escritos? A escrita, acima de tudo, representa uma dimensão política e cultural, desse modo, o que nos leva ou que referência estes representam em nossos trabalhos? 


\section{REFERÊNCIAS}

CARVAlHO, Henri de. "Autocrítica" de E. P. Thompson em A Miséria da Teoria: teoria marxista e política, subjetividade e objetividade na História. Projeto História, São Paulo, n. 48, dez. 2013.

CASSOLI, Alessandro Theodoro. E. P. Thompson, L. Kolakowski: "o pensamento como produto da atividade prática". Programa de Pós-Graduação em Sociologia Política da Universidade Federal de Santa Catarina. Florianópolis, 2010.

DUAYER, Mario. Desencanto Revolucionário, Ininteligibilidade da história e apostasia de esquerda: E. P. Thompson sobre L. Kolakowski. Esboços, revista do Programa de Pós-Graduação em História. UFSC, Florianópolis, v. 11, n. 12, 2014.

FORTES, A; NEGRO, A. L.; FONTES, P. As peculiaridades de E. P. Thompson. In: THOMPSON. E. P. As peculiaridades dos ingleses e outros ensaios. Campinas: Editora da Unicamp, 2012.

HOBSBAWM, E. Como mudar o mundo: Marx e o marxismo. São Paulo: Companhia das Letras, 2012.

KOSELlECK, Reinhart. Futuro Passado. Contribuição à semântica dos tempos históricos. Rio de Janeiro: Contraponto, Editora PUC-RJ, 2006.

MACEDO, Francisco Barbosa. O (re)fazer-se da historiografia: a obra de E. P. Thompson na produção discente do Programa de Pós-graduação em História da Unicamp (1982 -2002). Tese em História Econômica, USP, São Paulo, 2017.

MARX, K. Grundrisse: manuscritos econômicos de 1857-1858: esboços da crítica da economia política. São Paulo: Boitempo; Rio de Janeiro: Ed. UFRJ, 2011.

THOMPSON, E. P. A miséria da teoria ou um planetário de erros: uma crítica ao pensamento de Althusser. Rio de Janeiro: Zahar Editores, 1981.

THOMPSON, E. P. As peculiaridades dos ingleses e outros artigos. Campinas: Unicamp, 2001.

THOMPSON, E. P. Carta Aberta a Leszek Kolakowski. Mimeografada. Disponível em: <https://ideiasconcretas.files.wordpress.com/2011/04/arquivo2.pdf. $>$. Acesso em: 17 dez. 2017.

RAMOS, Igor Guedes. Genealogia de uma operação historiográfica: Edward Palmer Thompson, Michel Foucault e os historiadores brasileiros da década de 1980. São Paulo: Cultura Acadêmica, 2015.

SILVA, S. Thompson, Marx, os marxistas e os outros. In: THOMPSON. E.P. As peculiaridades dos ingleses e outros ensaios. Campinas: Editora da Unicamp, 2012. 